\title{
Gold medals, vitamin V and miscreant sports
}

$I_{0}^{t}$ t's all but become an unofficial Olympic sport: garnering gold by eluding doping authorities. Ever-craftier miscreants dabble in performance-boosting pharmaceuticals one step ahead of testing capabilities, leaving viewers to marvel at freakish athletes whose necks are wider than their heads and thighs are wider than their waists. Some sports, such as weightlifting, seem little more than a competition between drug designers.

It's a far cry from the horror that ensued when drug testing was first introduced for the 1968 Winter and Summer Olympic Games and an athlete was busted, for of all things, drinking beer.

Now, citizens cross their fingers that the urine samples of their athletic favourites will pass muster and only wish that the embarrassment was as tame as that suffered by the Swedes when modern pentathlete Hans-Gunnar Liljenwall was stripped of a bronze medal for dipping into the local cerveza at the Mexico City Summer Games.

Subsequent developments over the ensuing 4 decades have forced the science of detecting performance-enhancing drugs to evolve drastically in the cat-andmouse game between those who develop new screening tests and those who constantly seek new ways to artificially boost performance while evading the law.

The latest advances on both sides will be on display at the upcoming Beijing Olympics, where officials expect to administer a record 4500 tests between Aug. 8 and 24 in the hunt for minute traces of any of the hundreds of substances banned by the World Anti-Doping Agency.

Much of the effort goes toward uncovering new and illicit uses for otherwise everyday pills and medicines that were "created for good reasons but are abused by athletes," says David Howman, director general of the Montréalbased agency.

In that battle, Viagra (sildenafil citrate) has surfaced as the latest everydayproduct-turned-performance-booster.

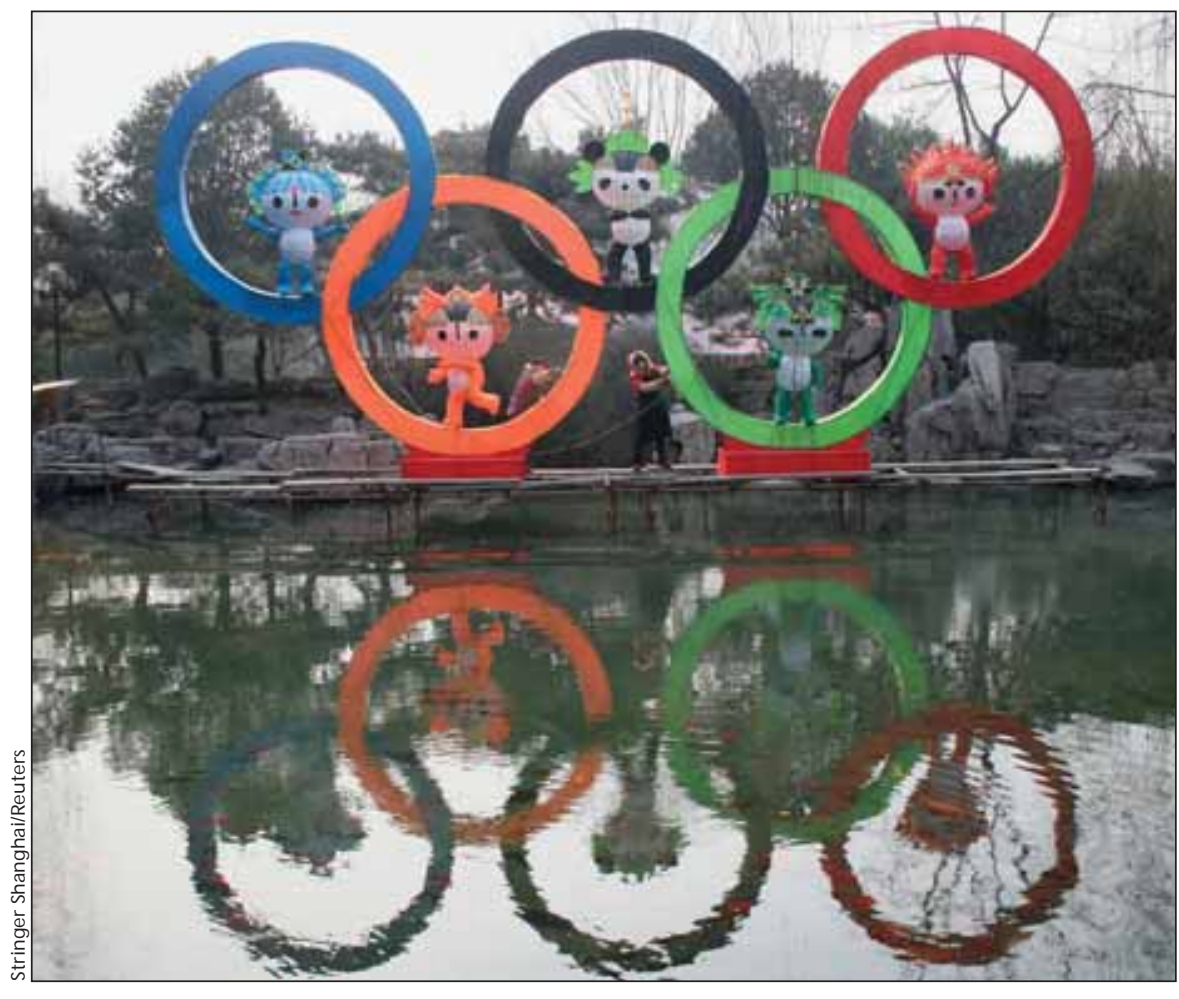

Fuwa, the official mascot of the Beijing 2008 Olympics, is depicted here in a lantern featuring the 5 Olympic rings, which represent the 5 major regions of the world: Africa, the Americas, Asia, Europe and Oceania. At least 1 of the 5 colours of the rings - blue, yellow (appears orange in photo), black, green and red - can be found in every national flag of the world.

World Anti-Doping Agency officials confirmed in June that they are studying the drug for potential inclusion on the list of banned substances. Athletes are said to be popping the antiimpotence pill because it increases blood flow to the lungs, thereby boosting cardiovascular capacity. One study found that in some cases the pill improved cyclists' times on a 6-kilometre course by up to $15 \%$ (J Applied Physiology 2006;100:2031-40).

The pill also made headlines for turning up in the lockers of professional baseball players, becoming the latest chapter in the sport's growing drug scandal. A cyclist at a race in Italy in May was busted when 82 Viagra pills, and syringes hidden inside tubes of toothpaste, were found inside his father's car.

Compounding the lure for athletes in
Beijing (once known as Peking) is the widespread belief that the little blue pill's cardio boost will offset the effects of smog in the capital of the People's Republic of China.

So concerned about pollution are Olympic authorities that they are allowing asthmatic athletes to use inhalers to stave off the air's effects.

In the face of such concerns, it's expected Viagra use will soar in Beijing, particularly as its use will be permitted. Results of the Viagra tests announced by the World Anti-Doping Agency are not expected until sometime in 2009, meaning 2010 is the earliest a ban could be put in place.

Yet the environmental conditions in Beijing are hardly the entire explanation for the increasing number of instances in which Viagra is surfacing in 
the medicine cabinets of an abnormally high number of athletes.

Either it's a new-found performancebooster or there's an eyebrow-raising prevalence of impotence amongst the world's top athletic performers.

Doping authorities appear entirely skeptical of the latter hypothesis. Yet stickhandling between those taking the substance for legitimate cause and those who are looking for a boost creates a logistical nightmare.

"How on earth are they going to ban one of the most frequently taken medications in the world?" asks Dr. Chris- tiane Ayotte, director of the doping control laboratory at the l'Institut national de la recherche scientifique in Laval, Quebec, while discussing the prevalence of Viagra and Cialis use amongst athletes.

Before the World Anti-Doping Agency was formed in 1999 following a Tour de France doping scandal that rocked the cycling world, debates about the unexpected benefits of everyday products like caffeine (initially banned but then reinstated) and Sudafed, were few and far between. Efforts were largely focused on specialized sub-

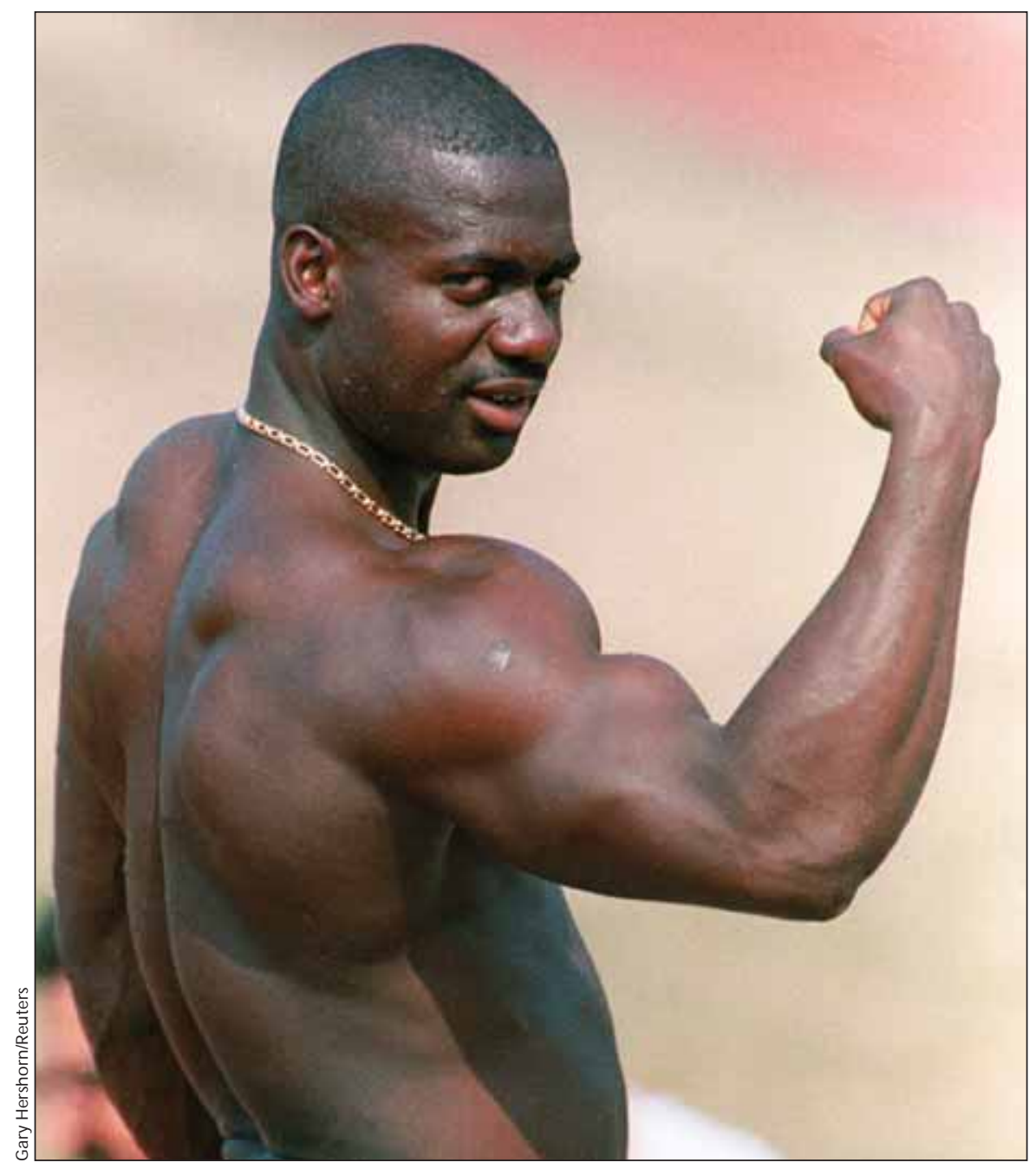

Sprinter Ben Johnson rocked Canada by testing positive for the testosterone-based anabolic steroid Stanozolol after winning the gold medal in the 100-metre dash at the 1988 Seoul Olympics. Runner-up American Carl Lewis promptly expressed shock and outrage. Johnson was stripped of his medal and it was awarded to Lewis. Roughly 15 years later, it was revealed that Lewis, who won 10 Olympic medals in his career, had tested positive for banned substances 3 times in the months before the 1988 Olympics, but the US Olympic Committee covered up the findings and cleared him to compete, as they did for hundreds of other US athletes who'd been dipping into the steroid box. The parade of disgraced athletes has essentially been unabated since. stances like steroids and those efforts were inconsistent.

But the doping landscape has been greatly professionalized since then.

Authorities trumpet the progress that has been made in catching those who cheat at the Olympics. But there have been few successes in addressing the systemic use that occurs between Games.

"We know we are not addressing the issue properly," particularly in the early stages of an athlete's career, Ayotte says. "The Olympics are unique but this is not the real life. The athletes do not start doping on the eve of their first Tour de France or their first Olympics."

Canada has often led efforts to curb doping, and has often been asked to introduce and monitor programs around the globe. It's a regime that in many respects is the product of national shock and embarrassment that ensued when sprinter Ben Johnson was stripped of a gold medal at the 1988 Olympics when his urine sample was found to contain the testosterone-based anabolic steroid Stanozolol.

Yet, the Seoul Olympics also heralded a decade in which anti-doping efforts sagged, fewer athletes were getting caught and as a result, public faith in the integrity of the system suffered.

Until then, there had been fairly steady progress, with most Summer Olympics producing anywhere between 6 and 12 doping busts (Box 1). But the numbers dropped conspicuously in the 1990s, bottoming out at 2 doping infractions at the 1996 Olympics.

Out of that came the World AntiDoping Agency, tasked with regaining some of the lost credibility. The effect was swift. At the 2000 Olympics, 10 athletes were caught doping, including 6 medalists, while a record 27 athletes were caught doping at the 2004 Olympics. The Beijing Olympics should demonstrate whether any of that has had a deterrent effect.

In total, 84 athletes, including 28 medal winners, have been caught doping at Summer Olympics, 37 of whom were weightlifters, the most notorious of sports amongst dopers (Box 2). The Winter Olympics have generally witnessed fewer tests and fewer doping busts. Since 1968, only 13 athletes, including 6 medal winners, have been 
caught doping. Seven of them were cross-country skiers and 4 were hockey players.

The increased number of positive tests is in part a function of the increased number of tests administered at each Games. At the 2000 Olympics, about 2000 doping tests were administered. That number grew to 3700 by the 2004 Olympics. Officials expect as many as 5000 tests will be conducted at the 2012 Olympics in London, England.

The increasing number is largely a result of the expansion of the rules governing who gets tested. In the past, the top 4 finalists in an event and 1 other athlete chosen randomly were subjected to tests.

But in Beijing, the top 5 athletes will be tested in addition to 2 chosen at random in each final. As well, random tests will be conducted throughout earlier stages of competition.

Beginning in 2000, Olympic athletes were also subject to pre-Olympic, out-of-competition testing to detect substances consumed prior to competition that wouldn't later appear on a test.

The sophistication of the tests has changed as well. Blood testing was introduced on a limited basis at the 1994 Winter Olympics and at the 2000 Summer Olympics. Urine remains the test subject of choice, but

\section{Box 1: Doping at the Summer Olympic Games}

According to the International Olympic Committee, there have been 84 infractions for doping since 1968, including such bizarre incidents as one in 2004 in which an Irish equestrian administered an antipsychotic to his horse. By Olympic Games, the failed, missed, refused or falsified tests (and medals forfeited) were:

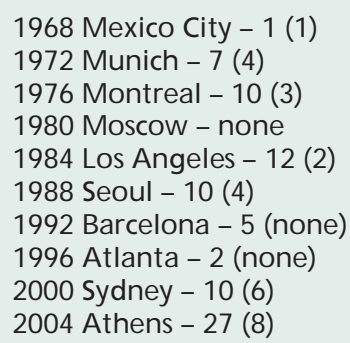

Source: International Olympic Committee

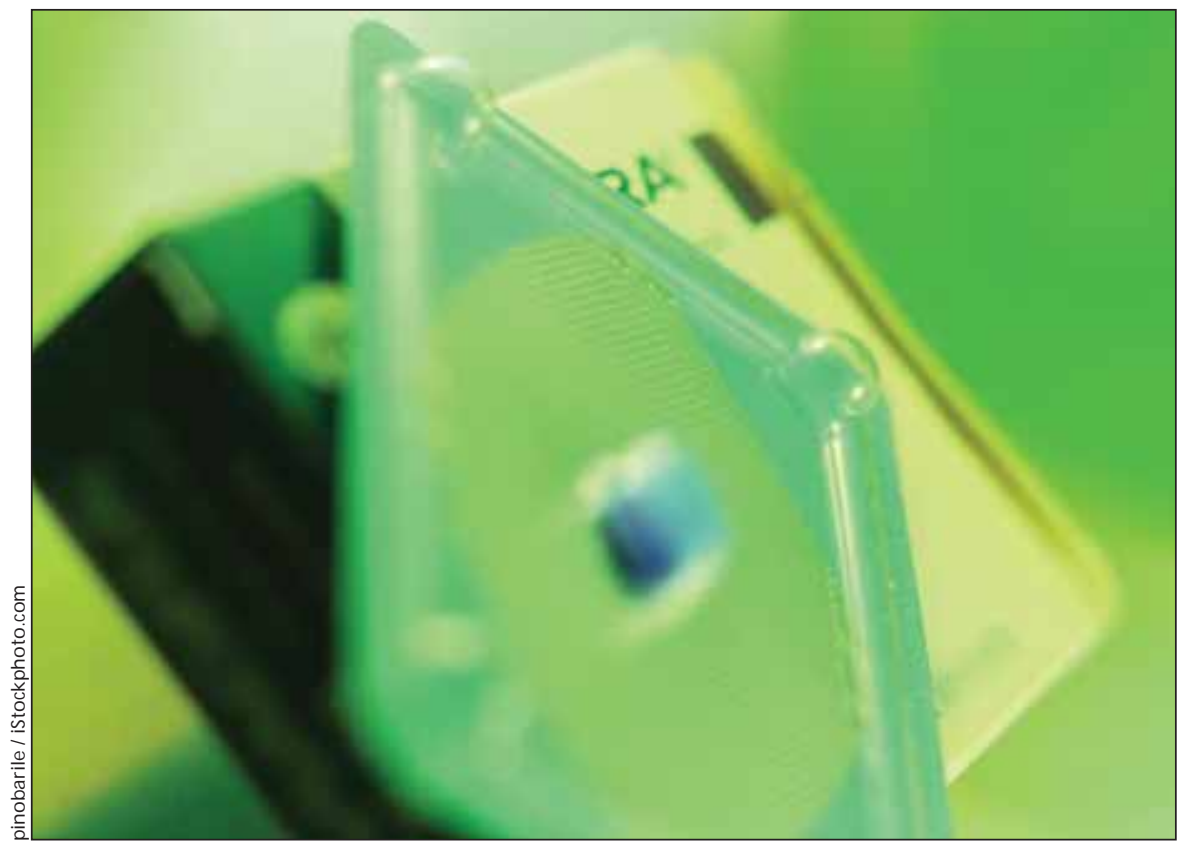

The cynical might suggest the Olympic motto - Citius, Altius, Fortius - ought be amended by the phrase "brought to you by Big Pharma." The latest drug of choice in the lockers of the world's athletic elite? None other than vitamin $\mathrm{V}$.

some drugs such as erythropoietin and human growth hormone are better detected in blood tests.

"We will be testing for [human growth hormone] in Beijing, using blood not urine," says Howman. "That's an advance."

It is the International Olympic Committee itself which will administer and monitor athlete testing in Beijing, not the World Anti-Doping Agency. The latter focuses on policies, regulations and monitoring the 33 facilities worldwide that have been approved for testing athletes' samples. An agencyapproved lab in Beijing, though, will handle the bulk of actual lab work. The agency will have 12 people in Beijing on an independent monitoring team, auditing the International Olympic Committee and its anti-doping efforts. Another dozen staff will work in the Olympic Village, distributing information to the athletes on anti-doping efforts and reminding them of what is and is not allowed.

At its annual summit late last year in Montréal, the World Anti-Doping Agency added several substances to its list such as selective androgen receptor modulators, a form of non-steroidal molecules similar to anabolic steroids in their effect. It also added any agents modifying myostatin functions, particularly myostatin inhibitors.

A ruling was also made on intravenous infusion. The agency prohibited such treatments except in the case of acute medical conditions.

"There has not been much change since 2006 on banned substances," Howman says. "It is more tidying up the list so that it is both scientifically and legally proofed to prevent challenges to the list." A complete list of prohibited substances is available at www.wada-ama.org.

Selective androgen receptor modulators are typical of sort of drugs now preferred by athletes. They are normally used to treat men who lack adequate amounts of the male sex hormones. But for athletes, they have potential to have the desirable effect of bolstering testosterone levels, which builds strength and bone density, without the less dangerous side effects typical of steroid use.

Myostatin inhibitors, similarly, are normally prescribed to patients suffering from muscle atrophy. But for athletes, the inhibitors remove the muscles' normal size regulators, thereby allowing the muscles to grow unencumbered. 


\section{Box 2: Medals forfeited during the Summer Olympic Games}

By country and sport, the number of medalsforfeited as a consequence of drug testing at Olympic Games since 1968, when the International Olympic Committee began testing athletes for banned substances. The lists do not include medals that were subsequently revoked, like the 3 gold and 2 bronze that were recently stripped from disgraced US sprinter Marion Jones after she admitted in court that sheíd been a persistent abuser of performanceenhancing drugs.

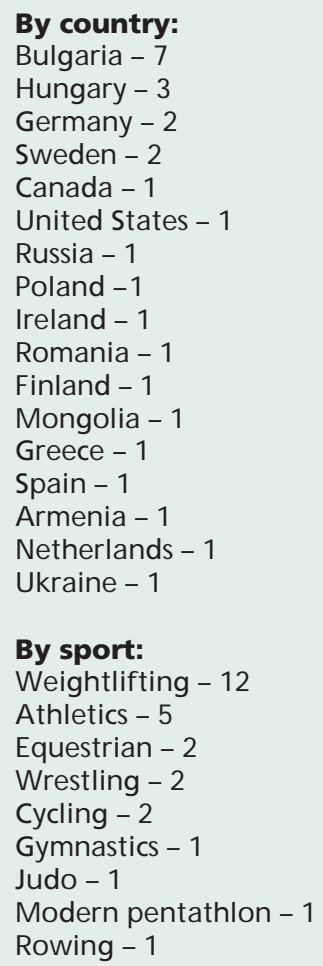

Neither of the groups has yet surfaced amongst athletes in competition testing. But the World Anti-Doping Agency added them to the list in a proactive move.

Authorities also say they are on particularly high alert because the Games are being held in Beijing. Many black market drugs originate from China and having the athletes in such close proximity to manufacturers risks making the drugs more readily available.

"There have been concerns in China," Howman says. "The greater concern is because that's where [black market drugs] come from."

It all seems a monumental task for an agency whose headquarters in Montréal does not match the image of a highly sophisticated lab where scientists work around the clock in the struggle to stay a step ahead of dopers. Rather, it is a simple office, where the agency coordinates various sporting bodies and governments and their policies on drugs.

About 50 staff work in the Montréal office, forming the bulk of the 60 people employed worldwide by the agency, which has smaller offices in Switzerland, Uruguay, South Africa and Japan.

"We have scientists, lawyers, antidoping protocol specialists and communications experts," says agency spokesman Frédéric Donzé, adding that about 15 nationalities are represented amongst the Montréal staff. "We have a very broad background."

Their work has expanded greatly since 1999, and their 2008 budget of US\$26.5 million is more than triple what they had to spend in their first year - a sign that as more and more individual sporting federations take on the responsibility of direct drug testing, there is much work to be done in coordinating and reviewing policies.

As well, there's the constant watch for new doping practices and inventive uses of everyday products. As past Olympics have proven, the Games are where previously unheard-of tactics surface.

Beijing will doubtless prove no exception. - Christopher Mason, Ottawa, Ont.

DOI:10.1503/cmaj.080993

\section{Medical Team Canada: bouncing to Beijing in aid of the medal haul}

$\mathrm{W}$ hen Canadian athletes arrive in Beijing to compete in the upcoming Summer Olympics, it will not necessarily be pulled hamstrings, broken bones or other traditional ailments that keep Team Canada's medical staff up at night.

Instead, their biggest challenge will be preparing elite athletes to perform in a steamy, smog-filled climate that could severely affect the respiratory and cardiovascular health of team members. That's because all the healthy hamstrings and strong muscles in the world will be of little use if an athlete is left unable to breathe comfortably.

In fact, concerns over air quality in Beijing have so worried Olympic officials that the International Olympic Committee ruled asthmatic athletes will be permitted to use inhalers in Beijing, under the therapeutic-use exemption.

\section{Box 1: Medical Team Canada}

The Canadian Olympic Committee says 41 medical staff will be dispatched to Beijing to support athletes as they vie for medals at the Games of the XXIX Olympiad. Those include 10 physicians, hailing from across the country, as follows:

Chief Medical Officer Dr. Robert McCormack (New Westminster, BC)

Assistant Chief Medical Officer Connie Lebrun (Edmonton, Alta.)

Dr. Alan Vernac (Montréal, Que.)

Dr. Julia Alleyne (Toronto, Ont.)

Dr. Mike Wilkinson (Vancouver, BC)

Dr. Teresa Lynn DeFreitas (Edmonton, Alta.)

Dr. Victor Lun (Calgary, Alta.)

Dr. Renata Frankovish (Ottawa, Ont.)

Dr. Andrew Pipe (Ottawa, Ont.)

Dr. Andrew Marshall (Ottawa, Ont.) 